CAHIER DE RECHERCHE \#0901E

Département de science économique

Faculté des sciences sociales

Université d'Ottawa
WORKING PAPER \#0901E

Department of Economics

Faculty of Social Sciences

University of Ottawa

\title{
Property Crime with Private Protection: A Market-for-Offenses Approach ${ }^{\#}$
}

\author{
Louis Hotte $^{*}$, Fabrice Valognes ${ }^{* *}$ and Tanguy van Ypersele $^{1}$
}

February 2009

\footnotetext{
\# This is a much revised version of an earlier draft. It has benefited from comments by Jean-Paul Azam, Jean-Marie Baland, Patrick Gonzalez, ChristianTritten and by seminar participants at the University of Namur, Laval University, University of Southampton, University of Ottawa, Carleton University, Université de Caen, University of Amsterdam and Institut d'études politiques de Paris. Remaining errors are ours

* Department of Economics, University of Ottawa, 55 Laurier E., Ottawa, Canada K1N 6N5 louis.hotte@uottawa.ca

F* Faculté des Arts et de l'Ingénieur (A.I.) / X, Dept of Economics and Mathematics, The University of Le Havre, F76057 Le Havre, Cedex France fabrice.valognes@univ-lehavre.fr

*** Université de Aix-Marseille 2, GREQAM, CEPR, Chateau La Farge, Route des Milles, 13290 Les Milles, France tanguy.vy@univ-aix.fr
} 


\begin{abstract}
We analyze property crime in an endowment economy composed of a large number of heterogeneous individuals who need to protect themselves, choose whether to participate in crime or not, and decide on how to allocate their predation efforts across victims. The equilibrium posits perfect foresight by all and the crime payoff clears the market between victims' losses and criminals' gains. We obtain that the crime payoff summarizes all the relevant information concerning the state of the crime environment as far as individual welfare is concerned. The burden of crime, expressed as losses relative to initial wealth, is evenly distributed between rich and poor individuals, inclusive of the protection effort. In absolute terms, the rich spend more on protection and lose more from crime. We derive a necessary and sufficient under which wealth redistribution increases crime. Under a weak sufficient condition, economic development tends to reduce the burden of crime for all, regardless of how its fruits are distributed. The predictions of the model accord well with existing empirical results
\end{abstract}

Keywords: Private Protection; Economic Development; Inequality

JEL Codes : D63, D74, K42, O17

\title{
Résumé
}

Nous analysons le crime contre la propriété en présence d'un grand nombre d'individus dont les niveaux de richesse varient. Chaque individu doit choisir son niveau de protection contre le vol, décider de voler ou non et, le cas échéant, allouer ses efforts de vol entre les victimes. Le concept d'équilibre utilisé suppose une prévision parfaite ainsi qu'un rendement du crime qui assure que les pertes des victimes soient égales aux gains des voleurs. Nous obtenons qu'en ce qui concerne l'individu, le rendement du crime incorpore toute l'information pertinente quant à l'état du crime dans l'économie. À l'équilibre, le fardeau du crime, exprimé en termes relatifs à la richesse initiale, est distribué également entre riches et pauvres, de même que le fardeau de la protection individuelle. En termes absolus, les riches dépenses cependant plus en protection mais se font également voler plus. Nous proposons une condition nécessaire et suffisante pour laquelle une redistribution plus égalitaire de la richesse contribue à hausser le crime. Le développement économique tend à réduire le fardeau du crime pour tous en autant qu'une condition suffisante - mais peu restrictive - soit respectée. Les prédictions du modèle correspondent étonnamment bien aux résultats des études empiriques existantes.

Mots-clé: Protection privée, développement économique, inégalité

Classification JEL: D63, D74, K42, O17 


\section{Contents}

1 Introduction 2

2 Fundamentals of the model $\quad 3$

2.1 The appropriation technology . . . . . . . . . . . . . 4

2.2 Information, sequence of decisions, and equilibria . . . . . 5

$\begin{array}{lll}3 & \text { Individual decisions } & 6\end{array}$

3.1 The allocation of crime efforts . . . . . . . . . . . . 6

3.2 The crime participation decision . . . . . . . . . . . . . . . 9

3.3 The individual protection level . . . . . . . . . . . . . . 11

4 Equilibrium conditions $\quad 12$

4.1 The equilibrium supply and demand for crime effort . . . . . . 12

4.2 The full market-for-offenses equilibrium . . . . . . . . . . . 13

5 Properties of the equilibrium $\quad 15$

5.1 Wealth levels and the burden of crime . . . . . . . . . . 16

5.2 Level of economic development . . . . . . . . . . . . . . 18

5.3 Inequality and crime . . . . . . . . . . . . . . . . . . . . 19

6 Conclusion 20

$\begin{array}{ll}\text { A Solving for the allocation of crime effort } & 21\end{array}$

B Proof of proposition 122

C Level of economic development 23 


\section{Introduction}

In the literature on the economics of crime, one typically finds public enforcement, private protection, legitimate wage opportunities and income distribution as fundamental determinants of property crime. It is also commonly recognized that these factors interact in order to yield an equilibrium level of crime. The precise way in which these interactions take place is thus crucial to our understanding of how economic development and income inequality affect the level of crime and how the burden of crime is distributed across the population. Our analysis is a contribution in this direction.

In order to account for the interactions between the different determinants of crime, we propose a "market-for-offenses" model of crime with heterogeneous individuals and endogenous supplies of crime efforts and demand for private protection. ${ }^{1}$ We put special emphasis on the role played by private protection, as many authors would agree on its crucial importance although it has been somewhat neglected up to now. ${ }^{2}$ To this end, we borrow from the literature on the economics of conflicts by defining an appropriation technology which transforms the respective predation and protection efforts of criminals and victims into respective gains and losses from crime.

We describe how a higher crime payoff increases individual welfare as it lowers the relative attractiveness of one's wealth. We tackle the issue of the distributive burden of crime by accounting for both losses from theft and the oft-neglected protection expenditures. We obtain that the burden of crime is evenly distributed across income groups if measured as a share of initial wealth. In absolute terms, the rich spend more on protection and suffer from a higher level of predation, though there is no difference between the rich and the poor in relative terms. An increase in average wealth has ambiguous effects on the absolute aggregate value of stolen goods but it reduces its importance relative to total wealth as well as contributing to lower the

\footnotetext{
${ }^{1}$ The expression "market-for-offenses" is borrowed from Ehrlich (1996).

${ }^{2}$ As Levitt (1999) points out, the burden of crime should also include the costs of individual protection. He reports that in the USA, "the home security business has grown at an annual rate of 10 percent over the last decade and is now a $\$ 14$ billion a year business". Shavell (1991) mentions that "private expenditures on security from crime exceed public expenditures" while DiIulio (1996) points out that the high rates of criminal victimization in inner-city areas can be partly explained by the lack of victims' financial resources to protect their homes. Surveys by Polinsky and Shavell (2000), Witte and Witt (2001) and Cook (2008) underscore the important role of private protection in explaining crime which is too often neglected.
} 
individual burden of crime. We also derive necessary and sufficient conditions under which wealth redistribution contributes to lower the crime level. Throughout the paper, we compare our results with those of the existing empirical literature on crime and find that they are quite consistent. The analysis attempts to provide a useful benchmark for further empirical work which could indirectly account for unobservable private precautions against crime.

In the literature, there are few examples of crime being modeled as a market. Notable exceptions include Furlong (1987), Fender (1999), Chiu and Madden (1998), and Imrohoroglu et al. (2000), though none considers the role played by private protection. Skogh and Stuart (1982), Usher (1987) and Shavell (1991) do consider private protection, but with homogeneous agents only. The main contribution of our analysis is thus to account for private protection decisions with heterogeneous victims and criminals, and where the crime payoff is endogenized in the market-for-offenses equilibrium. This approach is particularly suited for understanding the links between crime and economic development. The model presented in the survey by Ehrlich (1996) is closest in spirit to ours, the main difference being that our results are derived explicitly from micro-economic behavior.

As for the literature on conflict, we have found no instance of heterogeneous agents with a large number of players. ${ }^{3}$ The focus is on explaining large scale conflict rather than crime.

The paper is organized as follows: Section 2 presents the fundamental features of the model. Individual behavior is presented in section 3. The equilibrium conditions are derived in section 4 while comparative statics experiments are performed in section 5 . The conclusion proposes some extensions.

\section{Fundamentals of the model}

Each individual is initially endowed with a wealth - or productivity - level $a$, distributed continuously in the population according to $G(a), a \in(\underline{a}, \bar{a})$. When seen as a productivity measure, variable $a$ represents individual income and everyone inelastically supplies one unit of labor time. Either way, each is left with total wealth endowment $a$, which we shall refer to as wealth.

\footnotetext{
${ }^{3}$ Important contributions include Grossman (1995), Skaperdas (1992), Hirshleifer (1995) or Grossman and Kim (1995).
} 
Population size is normalized to one.

An individual's claim to her wealth is, however, not perfectly secure as others may attempt to appropriate a share of it. In response, efforts may be expended in order to preserve some, or all, of one's wealth. For ease of exposition, we shall consider a wealth endowment as a legitimate entitlement, so that its preserver is referred to as a victim, while other appropriators are termed criminals.

\subsection{The appropriation technology}

Each potential victim is indexed by her wealth $a$. The magnitude of a victim's loss decreases with her protection effort, denoted $y(a) \geq 0$, and increases with the sum of efforts that criminals spend trying to appropriate from her, denoted $x(a)$. Both display decreasing marginal productivities. Individuals may be victimized by more than one criminal. Hence, letting $I$ denote the total number of active criminals, we have $x(a)=\sum_{i=1}^{I} x_{i}(a) \geq 0$, where $x_{i}(a) \geq 0$ is the predation effort exerted by criminal $i$ against victim $a$. We therefore have the following technology: ${ }^{4}$

The appropriation technology The (expected) total share of victim $a$ 's wealth appropriated by criminals is given by function $\gamma(x(a), y(a)) \in[0,1]$ with the following properties: ${ }^{5}$

1. $\gamma_{x}>0, \gamma_{x x}<0, \gamma_{y}<0, \gamma_{y y}>0$;

2. $\gamma(x, y)$ is homogeneous of degree 0 in $(x, y)$;

3. $\gamma(0, y)=0, \forall y$.

The homogeneity assumption implies that the appropriated share really depends on the ratio of efforts $y(a) / x(a)$; that is, if the criminal and protection efforts are both increased by the same proportion, the share of wealth lost remains unchanged. Such an appropriation technology is referred to as a contest success function in the literature on conflicts. Two large classes are typically distinguished: the ratio form, adopted here, and the difference

\footnotetext{
${ }^{4}$ Subscripts denote derivatives.

${ }^{5}$ Agents being assumed neutral towards risk, it makes no difference to the analysis whether $\gamma(x, y)$ denotes an expected or a sure loss.
} 
form, which holds that the degree of success depends on the difference between effort levels rather than the ratio. In the present context, the ratio form seems more appropriate, though we admittedly cannot be sure. The match between the predictions of our model and the empirical results presented below does not contradict the present choice. ${ }^{6}$

\subsection{Information, sequence of decisions, and equilibria}

Individual wealth is assumed to be perfectly and costlessly observable by all. ${ }^{7}$ The probability and severity of punishment for criminals is set exogenously (see figure 1). With this knowledge, potential victims make the first decision by simultaneously and non-cooperatively choosing their protection level $y(a)$. Then, after observing both $a$ and $y(a)$, individuals decide whether to participate in crime or not. For those who choose to enter crime, they must decide on how to allocate their efforts across victims. Criminals also decide simultaneously and non-cooperatively. The crime market clears with a crime payoff which insures that the criminals' expected gains equals the victims' expected losses.

The model is static in the sense that time does not play an explicit role. The information structure, however, does imply a sequence in the decisions being made, as criminals can observe the victims' protection levels. Hence, when choosing a protection level, a victim will account for the criminals' reaction to it. And although victims decide simultaneously, the perfect information setting implies that they can and do anticipate correctly the final equilibrium. The equilibrium conditions thus assumes perfect foresight by all. Note that all actors are assumed to behave as risk-neutral, expected-wealth maximizers.

As can be noted, all decisions are being made in a decentralized, noncooperative fashion by a large number of heterogeneous agents. The characterization of such a crime equilibrium in the presence of private protection constitutes a theoretical novelty of this paper, as far as we know. Though stylized, the model yields some predictions that fit well with observations.

\footnotetext{
${ }^{6}$ See Hirshleifer (1989) for a discussion about the forms of contest success functions..

${ }^{7}$ Lacroix and Marceau (1995) consider the case where victim's wealth is not observable but protection may reveal that information to thieves.
} 


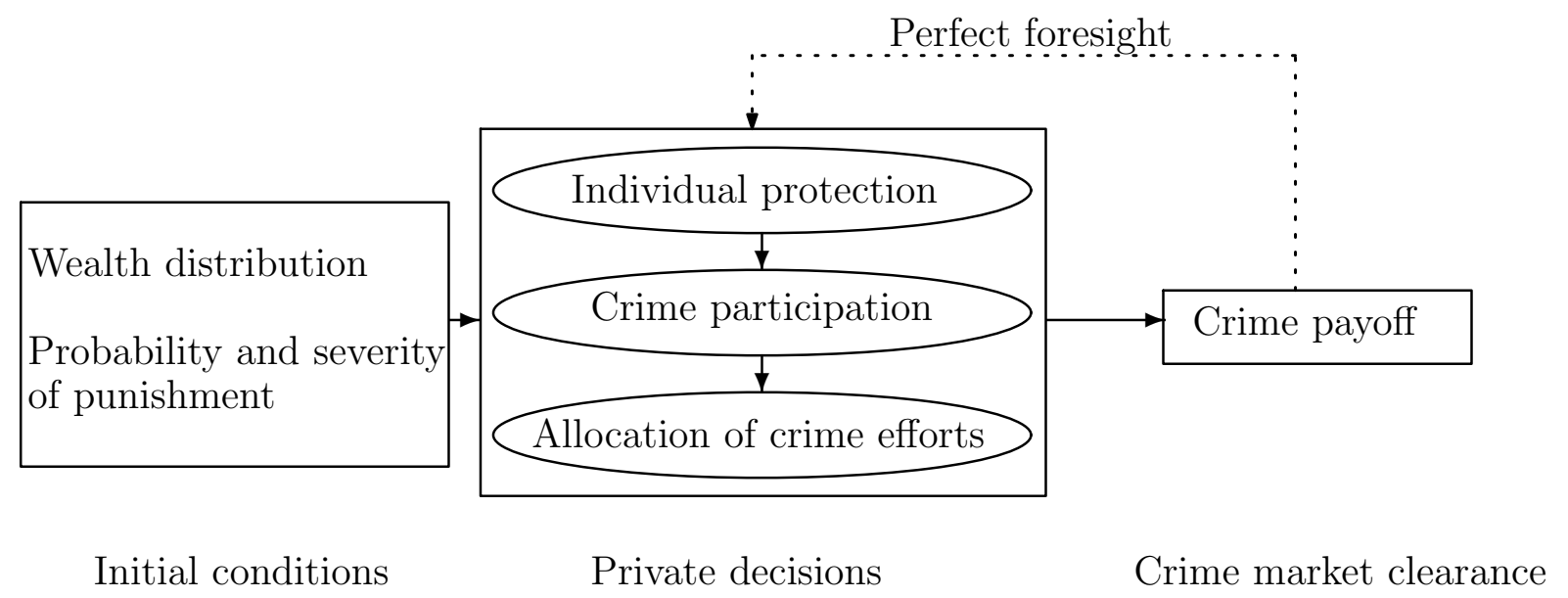

Figure 1: Structure of the crime market

\section{Individual decisions}

Each individual has three types of decisions to make, in the following sequence: (i) choosing the level of protection effort; (ii) whether to take part in crime or not; (iii) if one takes part in crime, how to allocate the crime efforts across victims. We therefore begin with the latter.

\subsection{The allocation of crime efforts}

Once a criminal decides to participate in crime, he supplies inelastically one unit of crime effort. For concreteness, we shall refer to this unit effort as one unit of time. This time can be broken down into parts that must be allocated between potential victims. Hence, $x_{i}(a)$ denotes the amount of time that criminal $i$ spends trying to take from victim $a$. This may include information gathering about a victim's habits, the location of her belongings, waiting for the right moment to steal, as much as the eventual break-in time. We must therefore devise a rule that characterizes the distribution of efforts across victims. Given the static nature of the model, we shall make use of the Nash equilibrium concept between criminals as follows.

The decision to visit any particular victim, and for how long, is taken by all criminals, simultaneously and irrevocably. Criminals can move costlessly 
and instantly between victims and are equally productive at taking from a given victim. ${ }^{8}$ Hence, the share of wealth expected to be appropriated per unit of effort is equal to $\gamma(x(a), y(a)) / x(a)$, which we define as the following average appropriation function:

$$
\phi(x(a), y(a)) \equiv \frac{\gamma(x(a), y(a))}{x(a)},
$$

where $\phi_{x}<0$ and $\phi_{y}<0$ as per the assumed properties of $\gamma(x(a), y(a))$.

For the time being, we solve for the Nash equilibrium between criminals taking as given the victims' protection levels $y(a)$ which, for clarity of exposition, are removed from the problem for now. We also take as given the number $I$ of participating criminals for now. The problem of a particular criminal $k$ can be expressed as follows:

$$
\begin{aligned}
\max _{\left\{x_{k}(a)\right\}} V_{k} & =\int_{\underline{a}}^{\bar{a}} x_{k}(a) \phi\left(x_{-k}(a)+x_{k}(a)\right) a g(a) d a, \\
\text { s.t. } & \int_{\underline{a}}^{\bar{a}} x_{k}(a) g(a) d a=1,
\end{aligned}
$$

where $x_{-k}(a)=\sum_{i \neq k} x_{i}(a)$.

Criminal $k$ maximizes his total crime income by deciding on how to allocate his efforts across victims, given his time constraint and for any allocation of aggregate efforts by other criminals. It is shown in Appendix A that the following condition must hold in equilibrium:

$$
\left(\phi(x(a))+x_{k}(a) \phi^{\prime}(x(a))\right) a=v, \forall a,
$$

where $v$ is the endogenously determined crime payoff per unit of effort. Condition (4) states that a rational criminal equalizes the marginal product of his own effort across the victims. But it does not imply that in equilibrium, the marginal products of crime efforts are globally equalized between victims. Indeed, the crime effort exerted against victim $a$ by any criminal reduces the unit return by $\phi^{\prime}(x(a))$ for all criminals present, though each criminal only

\footnotetext{
${ }^{8}$ They will however differ with respect to their opportunity cost because of public enforcement, as will be seen in section 3.2. Piccione and Rubinstein (2007) study the case where agents have varying ability to coerce in the absence of public enforcement, which they term the jungle equilibrium.
} 
accounts for his own share $x_{k}(a)$. This negative externality between criminals implies that as far as the aggregate returns from criminal activities are concerned, criminals will not maximize their aggregate booty.

We now wish to characterize the equilibrium when the number of criminals is considered arbitrarily large. The following proposition is derived in Appendix B:

Proposition 1 When the number of criminals is arbitrarily large, the Nash equilibrium allocation of crime efforts between victims is such that the average return is equalized between victims; that is,

$$
\phi(x(a)) a=v, \forall a .
$$

Condition (5) indicates that in an economy with an arbitrarily large number of criminals, crime efforts are distributed across victims until average returns are equalized. Figure 2 illustrates this result for the case of two victims with differing wealth but equal protection effort: although the wealthier victim attracts more crime efforts, the return per unit of effort is equalized. Hence, when criminals see a relatively wealthy target with little protection, they will collectively end-up spending much time and effort against him. But it would not be sensible for them to concentrate all efforts on the wealthiest targets only, as the average payoff eventually drops. If criminals act rationally, poorer victims will not be forgotten either. ${ }^{9}$

Condition (5) also implies that from the perspective of criminals as a whole, the distribution of their efforts is inefficient since the the aggregate crime booty is maximized by equating marginal returns between victims. But to do so would require extraordinary high levels of coordination and cooperation between criminals; something that could only be achieved with organized crime, which seems like an unreasonable assumption to make in most instances of property crime. ${ }^{10}$

\footnotetext{
${ }^{9}$ Glaeser and Sacerdote (1999) hold a similar line of argument in that “... the returns per crime will rise with density as criminals choose only the more promising victims or criminals will select more victims and the returns per hour of criminal activity will rise with density." (p. S241)

${ }^{10}$ In fact, the nature of the problem is equivalent to that of the Cournot-Nash equilibrium with many firms or the problem of free-access to natural resources. Aggregate income could be increased by forming a cartel in the first case and enforcing exclusion in the second. But it is well documented that such types of collective action are fraught with failures. Crime being an illegal activity by definition, successful organization should be even more difficult to sustain in most settings.
} 


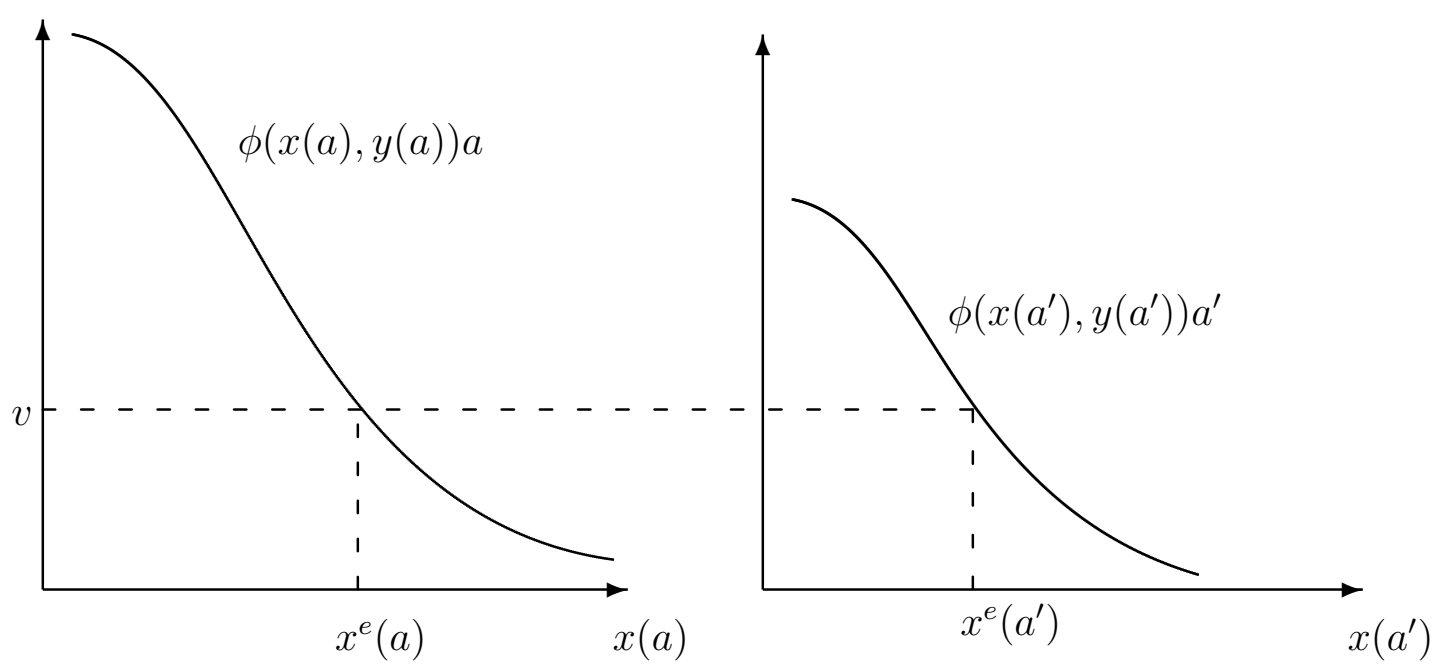

Figure 2: Distribution of appropriation efforts $\left(a>a^{\prime}\right.$ and $\left.y(a)=y\left(a^{\prime}\right)\right)$

In this section, we have defined how crime efforts will be distributed across victims, while taking as given the aggregate level of crime efforts and the protection effort of victims. We now turn to the crime participation decision.

\subsection{The crime participation decision}

The fact that criminals respond to economic incentives has been largely documented for most crime types, and especially for property crimes. Crime participation decisions are therefore made up, at least partly, of comparisons between the gains and costs. On the costs side, an extensive literature, both theoretical and empirical, has identified both the probability of detection and severity of punishment as significant determinants. ${ }^{11}$ Legitimate wage oppor-

\footnotetext{
${ }^{11}$ This observation was initially formalized in Becker (1968), while Polinsky and Shavell (2000) point out that Becker's model constitutes a formalization of ideas expressed earlier by Jeremy Bentham in 1789. Ehrlich (1973) confronts this theory with observations and finds that crime rates are negatively related to the probability and severity of punishment. Further studies tend to confirm the significant, negative effect of probability of apprehension on crime, though the effect of severity of punishment remains the subject of some controversy (Eide 2000, 360). For a survey of issues of empirical methodology, see Ehrlich (1996) or Witte and Witt (2001).
} 
tunities are also known to affect the opportunity cost of crime participation. ${ }^{12}$ In accordance with the empirical evidence, we shall therefore incorporate the fact that the opportunity cost of crime participation increases with the probability and magnitude of punishment and that punishment increases with income opportunities.

Let $p$ be the probability of a detection while punishment equals a fraction $1-\eta$ of an individual's ex-post wealth, $\eta \in(0,1)$. Then, for a risk-neutral individual with wealth $a$, crimes pays if and only if

$$
(1-p)(a+v)+p \eta(a+v)>a .
$$

Note that with a large number of participating criminals, individuals take the crime environment variable $v$ as given. ${ }^{13}$ Rearranging expression (6), the crime participation constraint reduces to the following

$$
v>\lambda a, \text { where } \lambda=\frac{p(1-\eta)}{1-p(1-\eta)} .
$$

Factor $a$ subsumes the effect of legitimate wage opportunities while parameter $\lambda$ accounts for probability and severity of punishment. The indifferent criminal will be referred to as the marginal criminal, denoted $\tilde{a}$, for which

$$
v=\lambda \tilde{a} .
$$

\footnotetext{
${ }^{12}$ Freeman $(1996,1999)$ surveys the evidence that labor market opportunities do affect individual decisions to participate in crime. Lott (1990) further finds that criminals with higher preconviction incomes lose more in terms of post-conviction incomes, and that this is often true in both absolute and relative terms. He also estimates that this reduction in post-conviction income constitutes a major part of the economic penalty imposed on criminals. A short survey by Corman and Mocan (2005), concerning the most recent studies which attempt to correct for difficult methodological issues, confirms that both sanctions and economic conditions have a significant impact on crime, although which of the two has a larger effect remains an unresolved issue.

${ }^{13}$ This is equivalent to assuming that firms take prices as given in a perfect competition context. Hotte and van Ypersele (2008) show that in the limit where the numbers of victims and criminals are arbitrarily large, the crime payoff can be taken as given. That said, the assumption of a large number of criminals here does not necessarily imply that crime is endemic within the community. It rather means that the number is large in absolute numbers, as per Nash equilibrium condition (5). Any number above one thousand would probably suffice to approximate a situation of "perfect competition" between criminals. But relative to a total population of, say, one million, this may not be considered an endemic proportion.
} 


\subsection{The individual protection level}

Let us reintroduce the protection variable explicitly. With crime payoff $v$, we have found in (5) that total crime efforts directed against any victim must respect the following condition:

$$
\phi(x(a), y(a)) a=v .
$$

This equality characterizes the implicit relation between the crime effort $x(a)$ suffered by an individual of wealth $a$ who spends effort $y(a)$ protecting her wealth when the crime payoff is $v$. It is convenient to express this implicit relation as $x(a, v, y(a))$.

Note how, by choosing protection effort level $y(a)$, the victim not only reveals a toleration for crime in terms of the share of his wealth that he expects to lose, but he also determines her individual demand for crime effort $x(a, v, y(a)) .{ }^{14}$ As may be expected, this demand is a direct function of wealth level $a$. But the crime payoff variable $v$ also plays a crucial role, in a way that will become clear below. Potential victims being neutral towards risk, they seek to maximize the value of their wealth, net of protection expenditures and the expected share lost to criminals. The problem is expressed as follows:

$$
\max _{y(a)} V(a)=[1-\gamma(x(a, v, y(a)), y(a))] a-y(a) .
$$

One can see from the problem of the victim that as far as each individual is concerned, $v$ summarizes all the relevant information about the crime environment that individuals care about in an anonymous crime market. This observation will be crucial to our understanding of welfare and crime in the general equilibrium setting.

The optimal protection level $y^{*}(a)$ is characterized by the following condition:

$$
\begin{aligned}
& \frac{\partial V(a)}{\partial y(a)}=-\left[\gamma_{x} \frac{\partial x(a)}{\partial y(a)}+\gamma_{y}\right] a-1=0, \\
& \text { where } \frac{\partial x(a)}{\partial y(a)}=\frac{\gamma_{y}}{\frac{\gamma}{x(a)}-\gamma_{x}}<0, \text { as per }(9) .
\end{aligned}
$$

The terms between square brackets reveal the two usual benefits from increased protection: the first is a deterrence effect which measures the drop

\footnotetext{
${ }^{14}$ See Cook (1986) for an analogous view on the demand for crime.
} 
in the crime effort directed against the particular victim; the second denotes the reduction in lost wealth for a given crime effort. The solution to the first-order condition determines the expected final wealth level $V^{*}(a)$ of an individual endowed with initial wealth $a$; that is, net of expected crime takings and protection expenditures:

$$
V^{*}(a)=\left[1-\gamma\left(x\left(a, v, y^{*}(a)\right), y^{*}(a)\right)\right] a-y^{*}(a) .
$$

We shall refer to $V^{*}(a)$ as the useful wealth.

\section{Equilibrium conditions}

\subsection{The equilibrium supply and demand for crime effort}

In the presence of a large number of criminals and victims, the state of the crime environment is taken as given at the individual level. But perfect foresight imposes a market-clearing condition under which the crime payoff $v$ equates the aggregate supply of crime efforts with the aggregate demand.

In order to allow for the fact that some individuals may never engage in criminal activities, due to other intrinsic and non-economic personal characteristics, we denote the proportion of potential criminals in the population as $\alpha \in(0,1)$. Consequently, the aggregate supply of criminal activities is characterized by

$$
x^{s}(v)=\alpha G(\tilde{a})=\alpha G\left(\frac{v}{\lambda}\right),
$$

where $\tilde{a}$ is the marginal criminal defined in (8).

Summing over all potential victims' demand for crime effort implied by (9), the aggregate demand amounts to the following:

$$
x^{d}(v)=\int_{\underline{a}}^{\bar{a}} x(a, v, y(a)) g(a) d a .
$$

In equilibrium, the crime payoff clears the aggregate supply and demands for crime; that is, $x^{s}\left(v^{e}\right)=x^{d}\left(v^{e}\right)$ or

$$
\alpha G\left(\frac{v^{e}}{\lambda}\right)=\int_{\underline{a}}^{\bar{a}} x\left(a, v^{e}, y(a)\right) g(a) d a .
$$

This equilibrium condition is illustrated in figure 3 for a given schedule $y(a)$, $a \in(\underline{a}, \bar{a})$. It is straightforward to verify that the equilibrium exists and is 


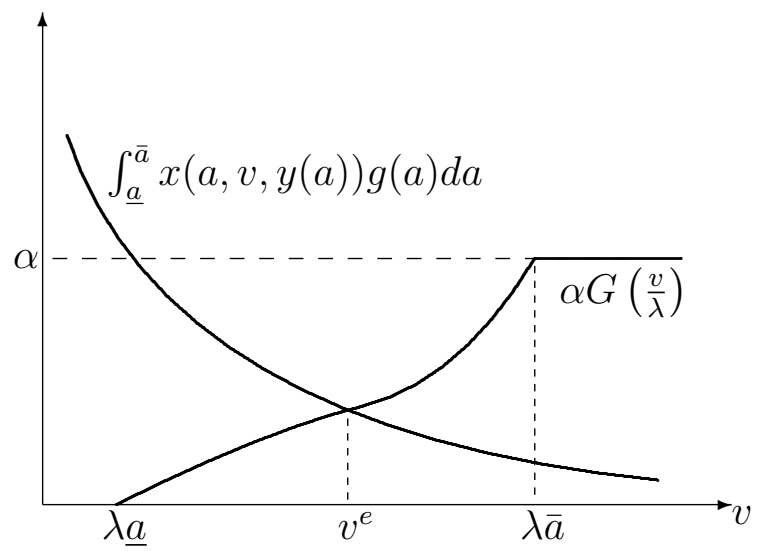

Figure 3: The equilibrium supply and demand for crime

unique. For low enough $\lambda$ or $y(a), a \in(\underline{a}, \bar{a})$, one can get equilibria in which the whole population engages in crime. Conversely, one can find a case where either $\lambda$ or $y(a), a \in(\underline{a}, \bar{a})$, are large enough to eliminate crime entirely. ${ }^{15}$

\subsection{The full market-for-offenses equilibrium}

Together, equations (9), (15) and (11) describe fully the market-for-offenses equilibrium: (9) determines how much crime effort each victim is subjected to, given her protection effort and the crime payoff; (15) matches the aggregate supply and demand for crime efforts; while (11) characterizes each victim's choice of protection effort. The endogenous variables are $x(a), y(a)$ and $v$.

It turns out that the analysis can be greatly simplified if we make use of the homogeneity property of the appropriation function. Indeed, since $\gamma(x, y)=\gamma(1, y / x)$, let us define the following function:

$$
\rho(r) \equiv \gamma(1, r), \text { where } r \equiv \frac{y}{x} \text {. }
$$

Rearranging condition (9) yields the following:

$$
\begin{aligned}
& x(a)=\frac{\rho(r(a))}{v} a, \\
& y(a) \equiv r x(a)=\frac{r(a) \rho(r(a))}{v} a .
\end{aligned}
$$

\footnotetext{
${ }^{15}$ Note that the possibility of a complete elimination of crime is ruled out if $\lim _{x(a) \rightarrow 0} \gamma(x(a), y(a)) / x(a)=+\infty$.
} 
The victim's problem in (10) can now be expressed as

$$
\max _{r(a)} V(a)=\left[1-\rho(r(a))-\frac{r(a) \rho(r(a))}{v}\right] a .
$$

The first-order condition for this problem is

$$
\frac{\rho\left(r^{*}\right)}{\rho^{\prime}\left(r^{*}\right)}+r^{*}=-v
$$

Since $v$ is independent of victim type, the chosen protection-to-predation ratio $r^{*}(a)$ is the same for all. We can therefore drop wealth index $a$. On the other hand, since $r^{*}$ depends on $v$, it will be convenient to write $r^{*}(v)$ and $\rho\left(r^{*}(v)\right)$ or $\rho^{*}(v)$. Useful wealth can now be expressed as:

$$
V^{*}(v ; a)=\left[1-\rho^{*}(v)-\frac{r^{*}(v) \rho^{*}(v)}{v}\right] a .
$$

The full crime equilibrium simplifies to the following system:

$$
\begin{aligned}
& \alpha G\left(\frac{v^{e}}{\lambda}\right) v^{e}=\rho\left(r^{*}\right) \hat{a}, \\
& \frac{\rho\left(r^{*}\right)}{\rho^{\prime}\left(r^{*}\right)}+r^{*}=-v^{e}, \\
& x^{*}(a)=\frac{\rho\left(r^{*}\right)}{v^{e}} a, \\
& y^{*}(a)=\frac{r^{*} \rho\left(r^{*}\right)}{v^{e}} a,
\end{aligned}
$$

where $\hat{a} \equiv \int_{\underline{a}}^{\bar{a}} a g(a) d a$ is a parameter that denotes the total initial wealth in the economy (or mean wealth level since the total population has been normalized to one).

The left-hand side of equation (22) measures the aggregate value of stolen property received by thieves. It is strictly increasing in $v$ and illutrated in figure 4 by curve $X_{S}$. The right-hand side of (22) measures the aggregate value of stolen property lost by the victims and is illustrated in figure 4 by curve $X_{L}$. Since $r^{*}$ depends on $v$ as per equation (23), $X_{L}$ is strictly decreasing in $v$. By continuity, the equilibrium exists and is unique. In figure $4, X^{e}$ and $v^{e}$ respectively denote the equilibrium aggregate value of stolen property and the crime payoff per unit of effort. 


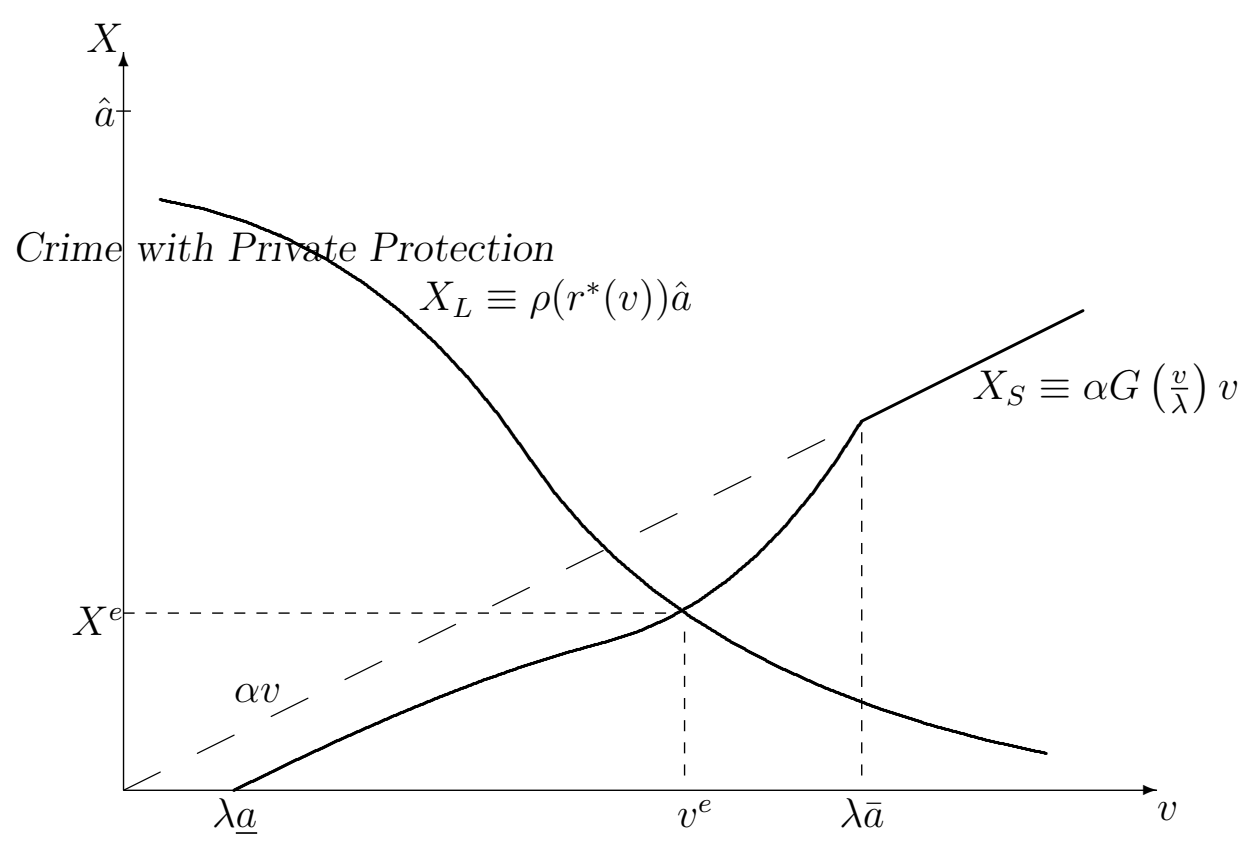

Figure 4: The Equilibrium Level of Crime

\section{Properties of the equilibrium}

Applying the envelop condition to equation (21), the total derivative of useful wealth with respect to any policy or event $z$ yields

$$
\frac{\partial V^{*}(a)}{\partial z}=\left[1-\rho\left(r^{*}\right)-\frac{r^{*} \rho\left(r^{*}\right)}{v^{e}}\right] \frac{\partial a}{\partial z}+\frac{r^{*} \rho\left(r^{*}\right)}{\left(v^{e}\right)^{2}} a \frac{\partial v^{e}}{\partial z} .
$$

Individuals will be ultimately concerned about how any policy or event affect two variables: their initial wealth $(a)$ and the equilibrium crime environment $\left(v^{e}\right)$. We shall refer to the first effect as the wealth effect and the second as the crime-payoff effect.

The welfare effect refers to the direct cost of a policy or event and its sign is straightforward. As for the crime-payoff effect, it indicates, somewhat surprisingly, that any policy or event that increases the crime payoff improves welfare. How can an increase in the crime payoff improve welfare? This is best understood with the help of figure 2 where, for given $y(a)$, an increase in $v$ results in a reduction in the amount of crime effort directed against victims. Indeed, given that average returns to appropriation are decreasing in $x(a)$, an increase in $v$ must be compensated for by a reduction in $x(a)$. In plain words, the increased crime payoff in the rest of the economy makes one's property relatively less attractive and thus easier to protect. This result is summarized as follows:

Proposition 2 As a general rule, individuals will benefit (lose) from a crime policy or event that increases (lowers) the crime payoff $v^{e}$. 
Note that in much of the empirical and theoretical literature on the economics of crime, victimization rates are typically used to describe the state of crime in a society and its evolution. The amounts of effort put into committing a crime are usually ignored (certainly in large part due to the fact that it is difficult to observe). By construction, the present model offers the opposite approach: it concentrates on the application of crime efforts and does not say anything about single events. Both measures are probably important to understand crime - we shall return to this in the conclusion. In the meantime, we assert the following:

Proposition 3 At the individual level, the state of the crime environment is fully summarized by the equilibrium crime payoff $v^{e}$.

\subsection{Wealth levels and the burden of crime}

Let us define the individual burden of crime as the ratio between the useful wealth and the initial wealth $V^{*}(a) / a$. This ratio accounts for wealth losses due to both the expected value of stolen goods and the cost of private protection. From (21), (24) and (25), we observe that $V^{*}(a) / a, x^{*}(a) / a$ and $y^{*}(a) / a$ are all independent of $a$. Hence the following:

Proposition 4 Regardless of initial wealth, in equilibrium, all individuals spend the same share of their wealth on protection expenditures and expect to lose the same share of their wealth to crime. The burden of crime is therefore the same for all.

It goes without saying that this result rests on the properties of the appropriation function, particularly the homogeneity assumption. Its reasonableness is an empirical issue which should ideally be addressed in conjunction with further theoretical analysis involving different properties of the appropriation function. This goes beyond the scope of the present paper. Suffice to point out that existing empirical work typically ignores protection expenditures, while measuring exposure to crime as the probability of being victimized, regardless of the values involved. So as a rough check of the validity of the above result, we have used data from the International Crime Victimization Survey (ICVS) for the year of 1996 in order to compare the average losses from burglaries for high-income with low-income groups in different countries. ${ }^{16}$ Our groups were created simply by dividing the surveyed

\footnotetext{
${ }^{16}$ The ICVS is based on random population samples. It therefore avoids many biases stemming from the use of data based on reported crimes. See Newman (1999) for a
} 


\section{CHART 2 HERE}

Figure 5: Rich-to-poor ratios of stolen values

population into two groups of equal size, the richest half and the poorest half. The results are reported in figure 5 in the form of the ratio of average losses of high-income to low-income groups. Consistent with our results, the data suggests that richer individuals lose more in value terms than the poor.

The same data set was then used to compare the protection measures used by richer and poorer individuals. In this case, unfortunately, the ICVS does not directly provide the money amounts that individuals spend on protection. But they do provide the following list of individual crime protection measures: burglar alarms, watch dogs, special grills, special door locks, high fences and watch schemes. For each household, we have computed an index of protection effort equal to the number of measures adopted. For instance, a household using three of the six possible measures would have an index of three. For both income groups, we have calculated the average protection index and reported the ratio of rich-to-poor groups in figure 6 for different countries. Richer households tend to use more protection measures than poorer ones. In an admittedly crude manner, we take this as an indication that richer households expend more efforts in protecting themselves than poorer ones.

Together, figures 5 and 6 suggest that richer individuals lose more in terms of the value of stolen property even though they tend to protect themselves more. Those observations indicate that our model may not be too far off the mark. ${ }^{17}$

discussion of the problems of biases when using reported crimes. Note that we have chosen only those countries that had sufficient data.

${ }^{17}$ The empirical literature that looked into the rich versus poor issue mainly uses victimization rates as a measure of exposition to crime. Levitt (1999) finds for the USA that in 1974-75, poor households were less victimized by property crimes than richer households, but that the relationship was reversed in 1994-95. Glaeser and Sacerdote (1999) also find that US households with higher income suffer lower chances of being victimized. In Latin America, Gaviria and Pagés (2002) obtain that higher income households are relatively more victimized than lower income ones. Kesteren et al. (2000) emphasize the importance of the difference between macro- and micro-analysis, noting that poorer communities are usually associated with higher risk, but that within a community, richer individuals may be more at risk (p. 54). 


\section{CHART 1 HERE}

Figure 6: Rich-to-poor ratios of protection efforts

Note finally that if the equilibrium appropriated share were seen as a deterministic loss while poor people suffered more heavily from losing a given proportion of their wealth than rich people - the equivalent of decreasing relative risk aversion - then one concludes that in equilibrium, poorer individuals' welfare is more severely affected by crime. ${ }^{18}$

\subsection{Level of economic development}

We measure the level of economic development simply by the average wealth level $\hat{a}$ (see equation (22)). Economic development causes an increase in $\hat{a}$ and a variation of the wealth distribution function, which is now to be represented by $G(a ; \hat{a})$. The effect of development on the crime equilibrium is best pictured by figure 4: it causes an upward shift of curve $X_{L}$ and a movement of curve $X_{S}$ which depends on how the fruits of economic development are distributed among the population. Figure 7 illustrates a case where the effects of economic development are fairly well distributed among the population as curve $X_{S}$ shifts to the right to $X_{S}^{\prime}$ by roughly the same amount everywhere. In this example, the total value of stolen property and the crime payoff both increase.

The total effect of a change in $\hat{a}$ is analysed fully in Appendix C. We find that for the crime payoff to increase with $\hat{a}$, it is sufficient that $\frac{\partial}{\partial \hat{a}} G(v / \lambda ; \hat{a}) \leq$ 0 ; that is, an increase in the level of economic development reduces the proportion of people that are poorer than the marginal criminal, a rather weak condition. This being the case, one can see from equation (26), where variable $z$ is replaced by $\hat{a}$, that all those who do not directly benefit from economic development can still receive an indirect benefit through the effect on crime as $v^{e}$ increases. In other words, even though some individuals may not see their wealth increase with economic development, the additional wealth in the rest of the economy makes one's own wealth relatively less attractive in equilibrium, thereby making it easier to protect. The following noteworthy results are derived in Appendix C:

\footnotetext{
${ }^{18}$ May this explain the higher sensitivity of poorer voters to security issues in the 2002 French election?
} 


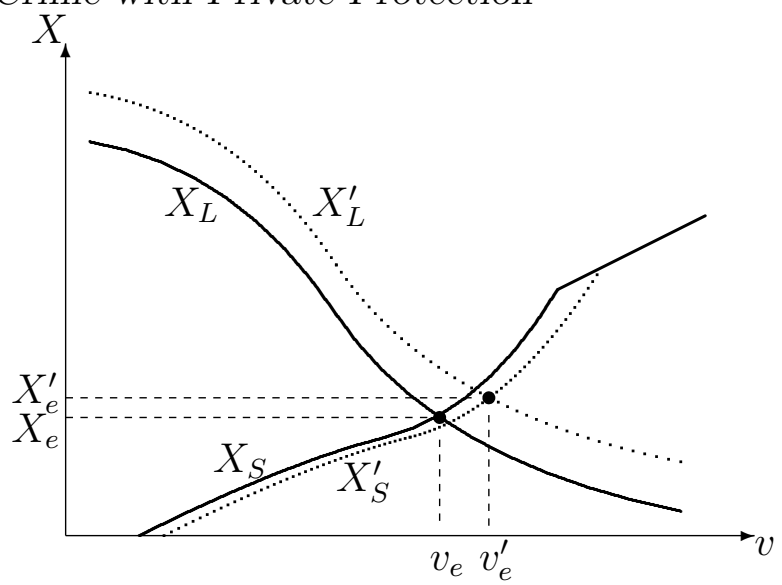

Figure 7: The Effect of Level of Economic Development on Crime

Proposition 5 Under a weak condition, economic development has the following effects: (i) it reduces the burden of crime for all; (ii) people are better protected in equilibrium (y/x increases); (iii) the aggregate value of stolen goods relative to wealth decreases; (iv) the new marginal criminal is characterized by a higher wealth.

Note that the effect on the absolute value of stolen goods remains ambiguous. Indeed, even though people are better protected, there is more wealth to steal. ${ }^{19}$ Moreover, the fact that people are better protected does not necessarily imply that they spend more on protection as the predation level $x(a)$ tends to go down.

\subsection{Inequality and crime}

We now consider the effects of a change in wealth distribution at constant total wealth $\hat{a}$. With fixed wealth, the aggregate amount that victims lose to crime for given $v$ does not vary; hence, curve $X_{L}$ is unaffected (see figure 4 ).

The total amount stolen by thieves will however be affected since a change in the distribution function $G(a)$ affects curve $X_{S}$. By inspection of figure 4 , one sees that whether the equilibrium crime payoff $v^{e}$ increases or not will depend on how the redistribution affects the proportion of individuals whose wealth falls below that of the pre-redistribution marginal criminal $\tilde{a}$. If

\footnotetext{
${ }^{19}$ This is consistent with the empirical work by Soares (2004) and Bourguignon et al. (2003) who find no specific link between crime rates and the level of per capita income.
} 
$G(\tilde{a})$ rises, then wealth redistribution has increased the number of individuals whose wealth falls below $\tilde{a}$, leading to a worsening of the crime environment ( $v^{e}$ decreases and $X^{e}$ increases). The opposite holds if $G(\tilde{a})$ is reduced after the redistribution.

Proposition 6 Wealth redistribution lowers the burden of crime if, and only if, it reduces the proportion of individuals whose wealth falls below that of the pre-redistribution marginal criminal.

To picture this, suppose that inequality is reduced in the sense that income distribution $G(a)$ becomes more concentrated around its mean $\hat{a}$ (see figure 8). If the marginal criminal's wealth is below the mean $(\tilde{a}<\hat{a})$, then curve $X_{S}$ shifts down at $v^{e}=\lambda \tilde{a}$ (compare the initial thin curve with the thick curve), thus leading to a clear improvement in the crime environment (higher $v^{e}$ and lower $X^{e}$ ). The opposite obtains if the marginal criminal's wealth is above the mean $\left(\tilde{a}>\hat{a}^{\prime}\right)$.

It turns out that this result accords well with the empirical work by Bourguignon et al. (2003), who emphasize the importance of concentrating on a specific part of the income distribution curve in order to measure how inequality affects crime. They find that in the case of Colombia, "that part of the population which most matters for time fluctuations in the crime rate are thus those individuals whose welfare lies below 80 percent of the mean of the whole population." According to our model, we leave it as an open question whether this implies that the marginal criminal in Colombia has an income of $80 \%$ of the mean. ${ }^{20}$

\section{Conclusion}

Our aim with this study was to fill a gap in the existing literature by introducing private incentives to invest in protection in a market-for-offenses model of crime. To this end, we introduced an appropriation function of the type commonly used in the literature on conflict. Along the way, we derived an allocation rule for criminals' predation efforts across victims which led to an equalization of the average crime payoff across victims.

\footnotetext{
${ }^{20}$ Soares (2004) also finds a significant positive effect of inequality on crime, but other previous work did not find any strong link (Bourguignon et al., 2003) . In a study conducted in rural Madagascar, Fafchamps and Minten (2006) conclude that an event that temporarily increases poverty results in more crop theft.
} 


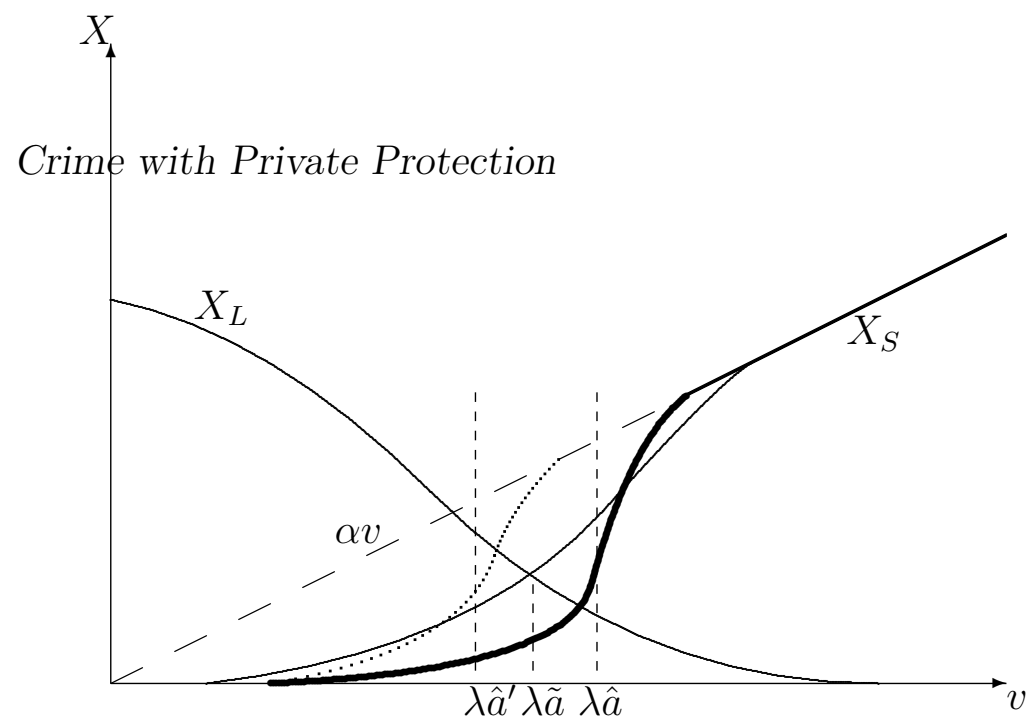

Figure 8: Income distribution and crime

We obtained that at the individual level, the crime payoff contains all the information regarding the state of the crime environment in the economy. In equilibrium, the rich tend to spend more on protection but they suffer more from predation. Relative to their wealth level, the burden of crime is equally distributed between income groups, inclusive of the protection efforts. Economic development has ambiguous effects on crime but it lowers the burden of crime for all individuals. Inequality also has ambiguous effects on crime though we propose weak conditions leading to unambiguous predictions.

In general, though the model is somewhat stylized, its predictions are surprisingly consistent with existing empirical results. A nice extension would be to introduce a minimum fixed cost of effort per victim. This would clarify the difference between crime effort level and victimization rate as discussed in section 5.1. The model could readily be used to study variations in public enforcement levels, how it affects the distribution of the burden of crime with political-economic implications regarding the demand for public enforcement as a substitute for private protection. Finally, one may want to account for the fact that individuals can normally choose between crime and work, thereby making total wealth endogenous.

\section{APPENDIX}

\section{A Solving for the allocation of crime effort}

The problem is equivalent to that of a dynamic optimization problem with an equality integral constraint. In order to solve for this, we create a state 
variable as follows: $\Gamma(a)=-\int_{a}^{a} x_{k}(s) g(s) d s$ such that $\Gamma^{\prime}(a)=-x_{k}(a) g(a)$, $\Gamma(\underline{a})=0$ and $\Gamma(\bar{a})=-1$. The problem is now conveniently expressed as

$$
\begin{aligned}
\max _{\left\{x_{k}(a)\right\}} V_{k}= & \int_{\underline{a}}^{\bar{a}} x_{k}(a) \phi\left(x_{-k}(a)+x_{k}(a)\right) a g(a) d a, \\
\text { s.t. } & \Gamma^{\prime}(a)=-x_{k}(a) g(a), \\
& \Gamma(\underline{a})=0, \Gamma(\bar{a})=-1 .
\end{aligned}
$$

The Hamiltonian for this problem is

$$
H=x_{k}(a) \phi\left(x_{-k}(a)+x_{k}(a)\right) a g(a)-v(a) x_{k}(a) g(a),
$$

where $v(a)$ is the costate variable associated with time constraint (3) and denotes the payoff from an additional unit of crime effort. Necessary conditions for a maximum are

$$
\begin{aligned}
& \frac{\partial H}{\partial x_{k}}=\left(\phi(x(a))+x_{k}(a) \phi^{\prime}(x(a))\right) a g(a)-v(a) g(a)=0, \\
& v^{\prime}(a)=-\frac{\partial H}{\partial \Gamma}=0 .
\end{aligned}
$$

Costate variable $v$ is thus independent of victim type. Hence, a criminal optimally allocates his efforts such that the marginal expected payoff of efforts are equalized across victims. Furthermore, condition (29) requires that the marginal payoff to crime effort be given by

$$
\left(\phi(x(a))+x_{k}(a) \phi^{\prime}(x(a))\right) a=v, \forall a .
$$

\section{B Proof of proposition 1}

We begin by showing that in equilibrium, it must be the case that each criminal exerts equal amounts of effort against any given victim, thereby imposing a certain symmetry to the Nash equilibrium.

Lemma 7 The Nash equilibrium is characterized by $x_{i}(a)=x_{j}(a), \forall i, j, a$.

Proof: Assume not and suppose that $x_{i}(a)<x_{j}(a)$ for some $a$. Then we have

$$
\left(\phi(x(a))+x_{i}(a) \phi^{\prime}(x(a))\right) a>\left(\phi(x(a))+x_{j}(a) \phi^{\prime}(x(a))\right) a .
$$

From condition 4 , this implies that $x_{i}(a)<x_{j}(a), \forall a$. Hence $\int_{\underline{a}}^{\bar{a}} x_{i}(a) g(a) d a<$ $\int_{\underline{a}}^{\bar{a}} x_{j}(a) g(a) d a$, in violation of constraint (3). 
Note that this does not imply that criminal efforts between victims will be distributed equally; that is, for $a \neq a^{\prime}$, we will generally have $x_{i}(a)=$ $x_{j}(a) \neq x_{i}\left(a^{\prime}\right)=x_{j}\left(a^{\prime}\right)$. The Nash equilibrium is thus characterized by

$$
\left(\phi(x(a))+\frac{x(a)}{I} \phi^{\prime}(x(a))\right) a=v, \forall a .
$$

It is straightforward to verify that this equilibrium is unique. Assuming now that $\lim _{x(a) \rightarrow \infty} \phi(x(a))=0$, then $\lim _{I \rightarrow \infty} x(a)$ is finite, otherwise condition (32) would be violated (given that $v>0$ ). As a result, we have

$$
\lim _{I \rightarrow \infty}\left[\left(\phi(x(a))+\frac{x(a)}{I} \phi^{\prime}(x(a))\right) a\right]=\phi(x(a)) a,
$$

which proves proposition 1 .

\section{Level of economic development}

Let us rewrite $(22)$ as follows $\psi^{A} \equiv \alpha G\left(\frac{v_{e}}{\lambda} ; \hat{a}\right) v_{e}-\rho\left(r^{*}\left(v_{e}\right)\right) \hat{a}=0$, where $r^{*}\left(v_{e}\right)$ is defined implicitly as per (23). Then

$$
\frac{\partial v_{e}}{\partial \hat{a}}=-\frac{\psi_{\hat{a}}^{B}}{\psi_{v}^{B}}>0
$$

since $\psi_{\hat{a}}^{B}=\alpha G_{\hat{a}}\left(\frac{v_{e}}{\lambda} ; \hat{a}\right) v_{e}-\rho\left(r^{*}\left(v_{e}\right)\right)<0$ if $G_{\hat{a}} \leq 0, \psi_{v}^{B}=\alpha g\left(\frac{v_{e}}{\lambda}\right) \frac{v_{e}}{\lambda}+$ $\alpha G\left(\frac{v_{e}}{\lambda}\right)-\rho^{\prime}\left(r^{*}\right) \frac{\partial r^{*}}{\partial v_{e}} \hat{a}>0$ and $\frac{\partial r^{*}}{\partial v_{e}}=-1 /\left(2-\frac{\rho(r) \rho^{\prime \prime}(r)}{\rho^{\prime}(r)^{2}}\right)>0$ by the secondorder condition. Hence, $\frac{\partial r}{\partial \hat{a}}=\frac{\partial r}{\partial v} \frac{\partial v}{\partial \hat{a}}>0$, $\frac{d X_{e}}{d \hat{a}}=\rho^{\prime}\left(r^{*}\right) \hat{a} \frac{\partial r^{*}}{\partial \hat{a}}+\rho\left(r^{*}\right) \gtreqless 0$, $\frac{d}{d \hat{a}}\left(\frac{X_{e}}{\hat{a}}\right)=\rho^{\prime}\left(r^{*}\right) \frac{\partial r^{*}}{\partial \hat{a}}<0$ and $\frac{\partial \tilde{a}}{\partial \hat{a}}=\frac{1}{\lambda} \frac{\partial v_{e}}{\partial \hat{a}}>0$. 


\section{References}

Ashenfelter, Orley C., and David Card, eds (1999) Hanbook of Labor Economics, vol. 3C (Amsterdam, The Netherlands: North-Holland)

Becker, Gary S. (1968) 'Crime and punishment: An economic approach.' Journal of Political Economy 76, 169-217

Bouckaert, Boudewijn, and Gerrit De Geest, eds (2000) Encyclopedia of Law and Economics (Edward Elgar and the University of Ghent)

Bourguignon, François, Jairo Nunez, and Fabio Sanchez (2003) 'A structural model of crime and inequality in colombia.' Journal of the European Economic Association 1, 440-449

Chiu, W. Henry, and Paul Madden (1998) 'Burglary and income inequality.' Journal of Public Economics 69, 123-141

Cook, Philip J. (1986) 'The demand and supply of criminal opportunities.' In Crime and Justice: An Annual Review of Research, ed. Michael Tonry and Norval Morris, vol. 7 (Chicago: University of Chicago Press) pp. 127

(2008) 'Assessing urban crime and its control: An overview.' Working Paper 13781, NBER, Cambridge, Mass.

Corman, Hope, and Naci Mocan (2005) 'Carrots, sticks and broken windows.' Journal of aw and Economics XLVIII, 235-266

Crime, UNICRI (United Nations Interregional, and Justice Research Institute) (1996) 'International crime victimization survey (ICVS)'

DiIulio, John J. (1996) 'Help wanted: Economists, crime and public policy.' Journal of Economic Perspectives 10(1), 3-24

Ehrlich, Isaac (1973) 'Participation in illegitimate activities: A theoretical and empirical investigation.' Journal of Political Economy 81, 521-565 (1996) 'Crime, punishment, and the market for offenses.' Journal of Economic Perspectives 10(1), 43-67

Eide, Erling (2000) 'Economics of criminal behavior.' In Bouckaert and Geest, eds (2000) chapter 8100, pp. 345-389. (Downloaded from http://encyclo.findlaw.com/index.html)

Fafchamps, Marcel, and Bart Minten (2006) 'Crime, transitory poverty, and isolation: Evidence from madagascar.' Economic Development and Cultural Change 54, 579-603 
Fender, John (1999) 'A general equilibrium model of crime and punishment.' Journal of Economic Behavior and Organization 39, 437-453

Freeman, Richard B. (1999) 'The economics of crime.' In Ashenfelter and Card, eds (1999) chapter 52, pp. 3529-3571

Freeman, Richerd B. (1996) 'Why do so many young american men commit crimes and what might we do about it?' Journal of Economic Perspectives 10(1), 25-42

Furlong, William J. (1987) 'A general equilibrium modle of crime commission and prevention.' Journal of Public Economic 34, 87-103

Gaviria, Alejandro, and Carmen Pagés (2002) 'Patterns of crime victimization in latin american cities.' Journal of Development Economics $67,181-203$

Glaeser, Edward L., and Bruce Sacerdote (1999) 'Why is there more crime in cities.' Journal of political economy 197(6), S225-S258

Grossman, Herschel I. (1995) 'Robin hood and the redistribution of property income.' European Journal of Political Economy 11, 399-410

Grossman, Herschel I., and Minseong Kim (1995) 'Swords or plowshares? a theory of the security of claims to property.' Journal of Political Economy 103(6), 1275-1288

Hirshleifer, Jack (1989) 'Conflict and rent-seeking success functions: Ratio vs. difference models of relative success.' Public Choice 63, 101-112 (1995) 'Anarchy and its breakdown.' Journal of Political Economy $103(1), 26-52$

Hotte, Louis, and Tanguy van Ypersele (2008) 'Individual protection against property crime: decomposing the effects of protection observability.' Canadian Journal of Economics 41, 537-563

Imrohoroglu, Ayse, Antonio Merlo, and Peter Rupert (2000) 'On the political economy of income redistribution and crime.' International Economic Review 41(1), 1-25

Kesteren, J. N. van, P. Mayhew, and P. Nieuwberta (2000) 'Criminal victimisation in seventeen industrialised countries: Key findings from the 2000 international crime victims survey.' Research and Policy Paper 187, Ministry of Justice, The Hague, Nederlands 
Lacroix, Guy, and Nicolas Marceau (1995) 'Private protection against crime.' Journal of Urban Economics 37(1), 72-87

Levitt, Steven D. (1999) 'The changing relationship between income and crime victimization.' Federal Reserve Bank of New York Economic Policy Review 5(3), 87-98

Newman, Graeme, ed. (1999) Global report on crime and justice (New York, USA: Oxford University Press)

Piccione, Michele, and Ariel Rubinstein (2007) 'Equilibrium in the jungle.' The Economic Journal 117, 883-896

Polinsky, A. Mitchell, and Stevens Shavell (2000) 'The economic theory of public enforcement of law.' Journal of Economic Literature 38(1), 45-76

Shavell, Steven (1991) 'Individual precautions to prevent theft: Private versus socially optimal behavior.' International Review of Law and Economics $11,123-132$

Skaperdas, Stergios (1992) 'Cooperation, conflcit, and power in the absence of property rights.' American Economic Review 82, 720-739

Skogh, Goran, and Charles Stuart (1982) 'A contractarian theory of property rights and crime.' Scandinavian Journal of Economics 84, 27-40

Soares, Rodrigo R. (2004) 'Development, crime, and punishment: Accounting for the international differences in crime rates.' Journal of Development Economics 73, 155-184

Usher, D. (1987) 'Theft as a paradigm for departures from efficiency.' Oxford Economic Papers 39, 235-252

Witte, Ann Dryden, and Robert Witt (2001) 'What we spend and what we get: Public and private provision of crime prevention and criminal justice.' Fiscal Studies 22, 1-40 
Crime with Private Protectio $h_{\text {hart 1: Rich-to-poor ratios of protection efforts }}$

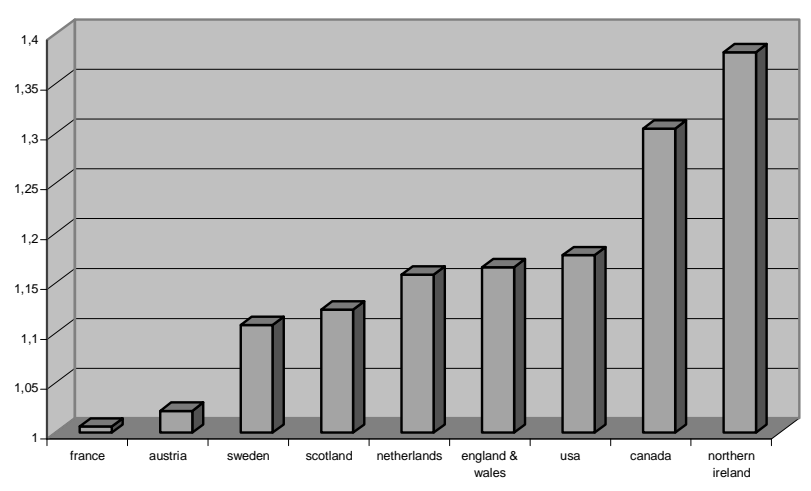

Chart 2: Rich-to-poor ratios of stolen values

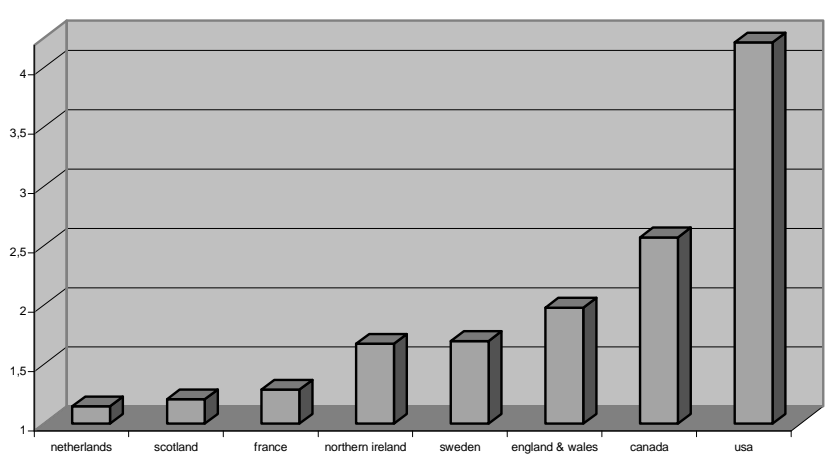

